\title{
NEW BIOMARKER OF OXIDATIVE DAMAGE IN PATIENTS WITH LEFT VENTRICULAR HYPERTROPHY
}

\section{González',2, C. Peralta², E. Granados², M. Roldán², M. Benito², B. Quintana ${ }^{1,2}$}

1 Anaesthesiology and Resuscitation Service General University Hospital Gregorio Marañón - Madrid (Spain), 2 Complutense University of Madrid - General University Hospital Gregorio Marañón - Madrid (Spain)

\section{BACKGROUND AND GOAL OF STUDY}

Left ventricular hypertrophy $(\mathrm{LVH})$ is a problem in the clinic. Oxidative stress has been implicated in LVH. Our research group investigates new therapies in the early regression of cardiovascular remodeling that act on biomarkers of oxidative stress $(1,2)$. The aim of the study is to search for new plasmatic oxidative stress biomarkers that allow the diagnosis of LVH and the search in the future of new therapies in patients with left ventricular hypertrophy (therapeutic target).

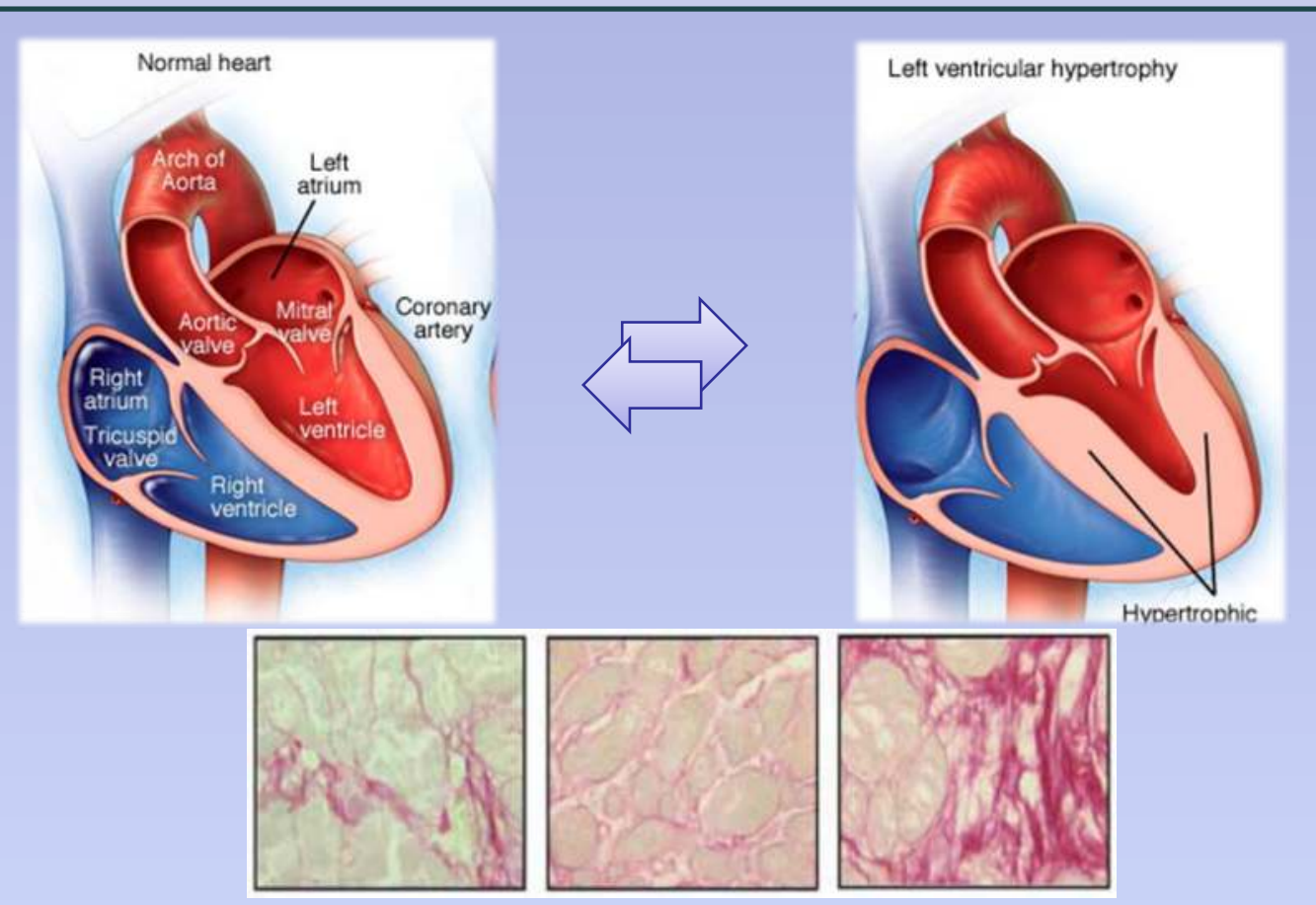

Figure 1. Left ventricular hypertrophy

\section{RESULTS AND DISCUSSION}

No significant differences were observed between both groups in the total thiols. However, we detected an increase in the thiolated proteins $(P<0.01)$ and TPI $(p$ $<0.001$ ) in the HVI Group with respect to the Control Group. The area under the ROC curve for PTI was of 0.75 (95\% Cl: 0.63-0.86). The regression model demonstrated that $\mathrm{PTI}$ is an independent risk factor $(\mathrm{P}=0.02$, OR $=$ 7.68, 95\% Cl: 1.37-42.99) for clinical variables (sex, age, arterial hypertension, diabetes mellitus, dyslipidaemia, renal insufficiency, coronary/valvular pathology).

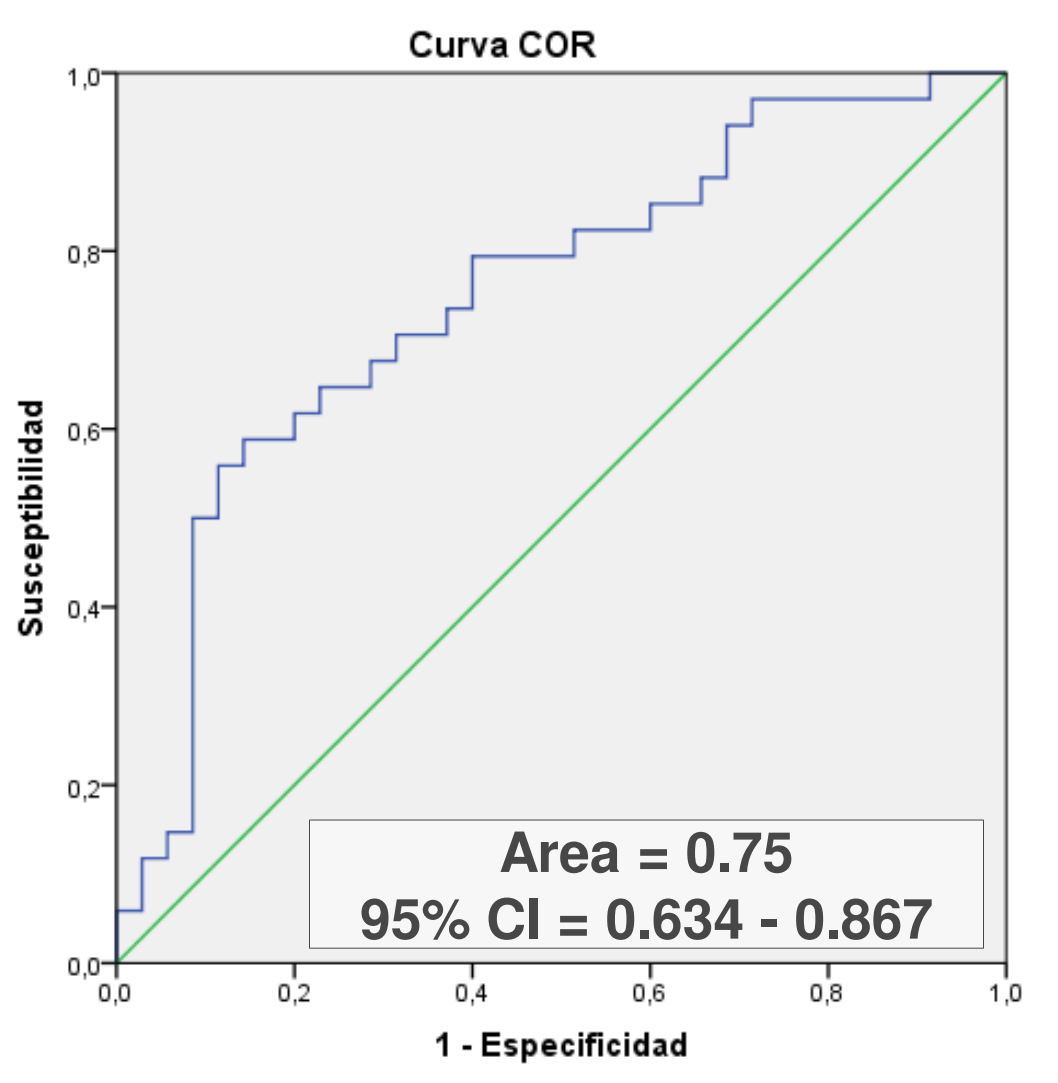

Figure 3. ROC curve analysis.

\section{CONCLUSION}

Our results suggest that TPI could be a specific biomarker of oxidative stress in patients with LVH

\section{MATERIALS AND METHODS}

Observational, prospective, non-randomized, comparative study of 2 groups of patients: LVH group $(n=35)$ and control group (without $\mathrm{LVH}, \mathrm{n}=35$ ). The echocardiographic study allowed the detection of patients with LVH. The extraction of a blood sample allowed us to study the variables of oxidative stress in the plasma of both groups: total thiols, thiolated proteins and thiolated protein index (TPI = thiolated proteins / thiols). The area under the curve for TPI was calculated and we use the logist regression analysis to estimate the association between TPI and clinical variables of interest. The biomarkers were compared in both group using student independent t-test. The data were expressed as mean \pm SEM. $\mathrm{P}<0.05$ was considered significant. All procedures were approved by the Ethics Committee of Hospital General Universitario Gregorio Marañon, Madrid, Spain.

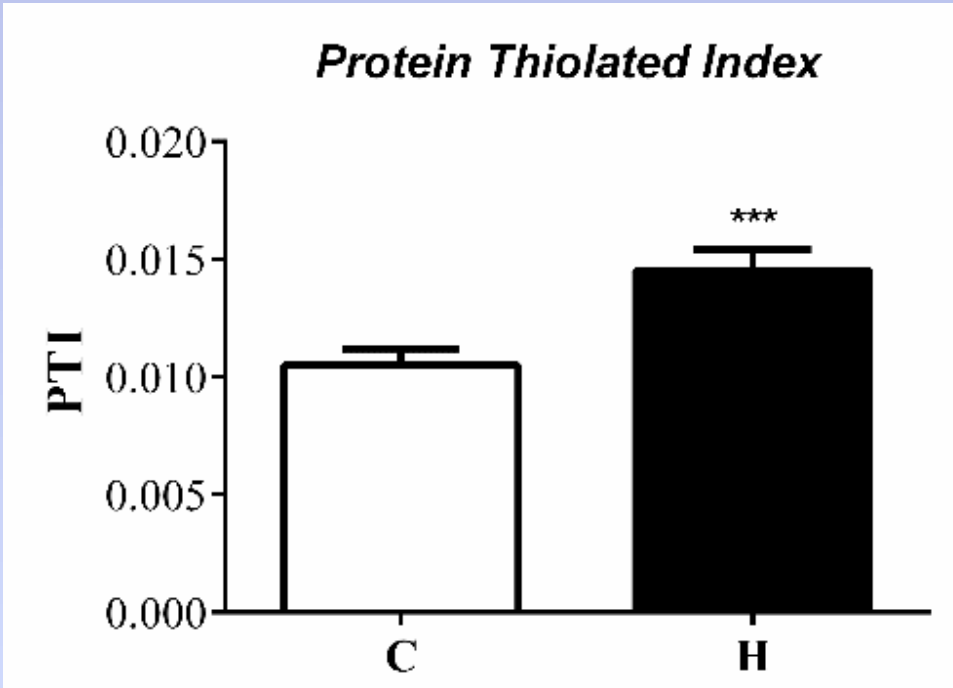

Figure 2. TPI and student independent t-test.

\begin{tabular}{|r|c|c|c|}
\hline & Group C $(\mathbf{n}=\mathbf{3 5})$ & Group H $(\mathbf{n}=\mathbf{3 5})$ & $\mathbf{P}$ \\
\hline Total thiols & $7.819 \pm 0.34$ & $7.414 \pm 0.38$ & 0.437 \\
\hline Thiolated proteins & $0.079 \pm 0.005$ & $0.102 \pm 0.006$ & 0.01
\end{tabular}

Table 1. Mean \pm SD of stress oxidative variables.

\begin{tabular}{|l|c|c|}
\hline \multicolumn{1}{|c|}{ Variables } & OR (95\% IC) & P \\
\hline PTI & $7.68(1.37-42.99)$ & 0.02 \\
\hline Gender & $3.05(0.07-13.22)$ & 3.05 \\
\hline Age & $1.07(1-1.14)$ & 0.06 \\
\hline Valvular pathology & $1.57(0.18-13.37)$ & 0.67 \\
\hline Coronary pathology & $6(1-35.9)$ & 0.06 \\
\hline Hypertension & $1.84(0.37-9)$ & 0.44 \\
\hline Mellitus diabetes & $1.95(0.33-11.25)$ & 0.45 \\
\hline Dyslipidemia & $0.74(0.17-3.27)$ & 0.69 \\
\hline Obstructive sleep apnea & $9.35(0.68-128.80)$ & 0.09 \\
\hline Renal failure & $0.39(0.08-1.82)$ & 0.23 \\
\hline
\end{tabular}

Table 2. Logistic regression analysis of variables.

Acknowledgments: Study financed by the Health Research Fund FIS 16/02069 and Fondos FEDER.

References:

1. Arnalich-Montiel A et al. BioMed Res Int 2014; 2014; 531087.

2. Quintana-Villamandos B et al. Hypertens Res 2016; 39: 692-700. 